\title{
The density of Robotization of Agriculture in Russia and its Regions
}

\author{
V.I. NABOKOV \\ Department of Economics, \\ Management and Law \\ South Ural State University \\ 454080, Chelyabinsk, Lenin Av, 76 \\ RUSSIA \\ E.A. SKVORTSOV \\ Department of Electronic \\ Engineering Ural Federal \\ University 620002, Ekaterinburg, \\ St. Mira, 19 RUSSIA
}

\author{
A.N. SEMIN \\ Department of Competition Law \\ and Antimonopoly Regulation \\ Ural State Economic University \\ Ekaterinburg, St. March 8 RUSSIA
A. S. GUSEV
Department of Land Management Ural State Agrarian University 620075, Ekaterinburg, St. Karl Liebknecht, 42 RUSSIA

\author{
N.K. PRYADILINA \\ Department of Economics and \\ Economic Security \\ Ural State Forest Engineering \\ University 620100 Ekaterinburg, \\ Siberian tract, 37 \\ RUSSIA
K.V. NEKRASOV
Department of World Economy and Logistics
Ural State University of Railway Transport 620034, Ekaterinburg,
St. Kolmo-gorova, 66 RUSSIA

\begin{abstract}
According to the Rosstat data a share of agricultural organizations which introduce technological innovations is low (2.7\%). The study aims to determine the density of agricultural robotization in Russia and its regions. The density of agricultural robotization is influenced by the average annual number of employees in the industry, which was 5802 thousand people in 2013-2019 and decreased by $22 \%$ over the studied period. The data show that 435 units of robotics were introduced in agricultural organizations in the Russian Federation in 2006-2019. The vast majority of robotics used in agriculture in Russia is milking robots mainly by European manufacturers. Robotics is used in the agricultural sector in the Central (185 units), Volga (95 units), NorthWest (66 units) and Ural (68 units) federal districts. The introduction of robotics in agriculture in the Southern, Siberian and North Caucasian federal districts is practically not carried out. The highest density of agricultural robotization is observed in the Kaluga (42.67 robots per 10 thousand employees in the industry), the Ryazan (14.8), the Sverdlovsk (6.32) and the Vologda Region (6.21). The results of the study will allow development of a mechanism that promotes priority robotization of rural areas where robotization is slow or is not carried out to prevent their technological lagging behind and the further development of a stagnation processes. The scientific significance of the research results will contribute to the development of theoretical aspects of robotics application in agriculture and the spatial aspects of robotization.
\end{abstract}

Key-Words: - robotization, agriculture, density of robotization, territorial development, robotics

Received: March 5, 2020. Revised: September 1, 2020. Accepted: September 13, 2020. Published: October 82020.

\section{Introduction}

As you can see for the title of the paper you must The rise in the living standards of the population, entering of foreign companies into the domestic market intensify competition at the food market and force agricultural organizations to improve technological processes to reduce the cost of production, to improve the quality, to search for new development principles, and to encourage a production output; thus, innovations including robotics are becoming essential. At the same time, in conditions of severe shortage and ongoing outflow of the population from rural areas, the problem of introducing of innovations and laborsaving innovative technologies with a creative component are of particular importance. 
At the same time, the robotization of certain regions and rural areas is difficult due to the lack of theoretical developments on this issue, insufficient knowledge about the feasibility of introducing robotics compared to traditional technologies, the lack of guidelines for the implementation of this technique, as well as systematic training of personnel capable of mastering robotics. Thus, it is necessary to search for new universal laws that will increase the attractiveness of agriculture for a new generation of graduates from agricultural higher schools and colleges, and create conditions for their retention. The robotization of the agrarian sector at rural areas can be carried out with using qualitatively new physical, socio-economic principles, information technologies and management systems.

\section{Problem Formulation}

When studying the process of robotization of agrarian production at the rural areas, it is necessary to consider regional characteristics and the specifics of the industry [1]. One can distinguish the features of spatial development of robotization of the agricultural sector, which are associated with the peculiarities of the rural areas [2]. These are the level and conditions of socio-economic development, the level of urbanization, the development of infrastructure, the demographic situation, the level of state support, the competitiveness of the agricultural sector and its ability to attract labor compared to other industries, etc.

The main scientific idea is that the robotization of agriculture is carried out with regional characteristics and peculiarities of specific sectors of agricultural production.

The study aims to determine the density of robotization of agriculture in Russia and the regions.

The research objectives are:

1. To determine a proportion of organizations engaged in technological innovations by types of economic activities.

2. To determine the density of agricultural robotization in the Russian Federation and its federal districts.

3. To rank the regions according to the density of robotization.

To analyze the activities on introduction of robotics in agriculture, the data from the Rosstat were used. And data inquiries were also made to the Ministry of Agriculture of the Russian Federation on the number of robotics introduced at the agricultural organizations (in dynamics), on the brands of this equipment. For certain regions, the data were specified in the regional ministries of agriculture and agro-industrial complex.

The indicator "density of robotization" is considered to be used. This indicator should be calculated as the ratio of the number of robotics used to the number of workers employed in agricultural production:

$$
\mathrm{P} \_\mathrm{r}=\mathrm{Nr} / \mathrm{Nw} * 10000,
$$

where, $\mathrm{Nr}$ - the number of robotics used in agriculture, units.

$\mathrm{Nw}$ - the number of workers employed in agricultural production.

This indicator is advisable to use per 10,000 workers employed in agriculture. The density of agricultural robotization in various regions will allow qualitative assessing of this process. It will also help identify regions with the most intense robotization of the agricultural sector and regions with a technological lag.

\subsection{The state of innovation in agriculture}

Recently, the state has been increasing attention to the processes of digitalization and robotization of the country's economy. The strategy of scientific and technological development of the Russian Federation until 2030 was adopted (The Decree of the President of the Russian Federation by December 1, 2016 No. 642 "On the strategy of scientific and technological development of the Russian Federation until 2030"). One of the priorities of this strategy is the transition within next 10-15 years to digital, intelligent production technologies, robotic systems. The implementation of the strategy will create the appropriate conditions and infrastructure for robotics, including rural areas, train personnel to achieve leadership in particular areas of scientific and technological development and make an integrated national innovation system. In order to implement this strategy, a plan of relevant measures was developed and adopted (The Decree of the Government of the Russian Federation by June 24, 2017 No. 1325-p "Plan of measures for the implementation of the Strategy for scientific and technological development of the Russian Federation"), which involves a mechanism and expected results of robotization. The scientific and technical program for agricultural development for 2017-2025 was also adopted and was aimed at solving the tasks of strategic development. The suggested measures of systemic support for the transition of agriculture to the use of robotics will encourage domestic competitive manufacturers to the world market. 
So, it is of particular interest to analyze the share of organizations that have carried out technological innovations in the Russian Federation and the types of economic activity (Figure 1).

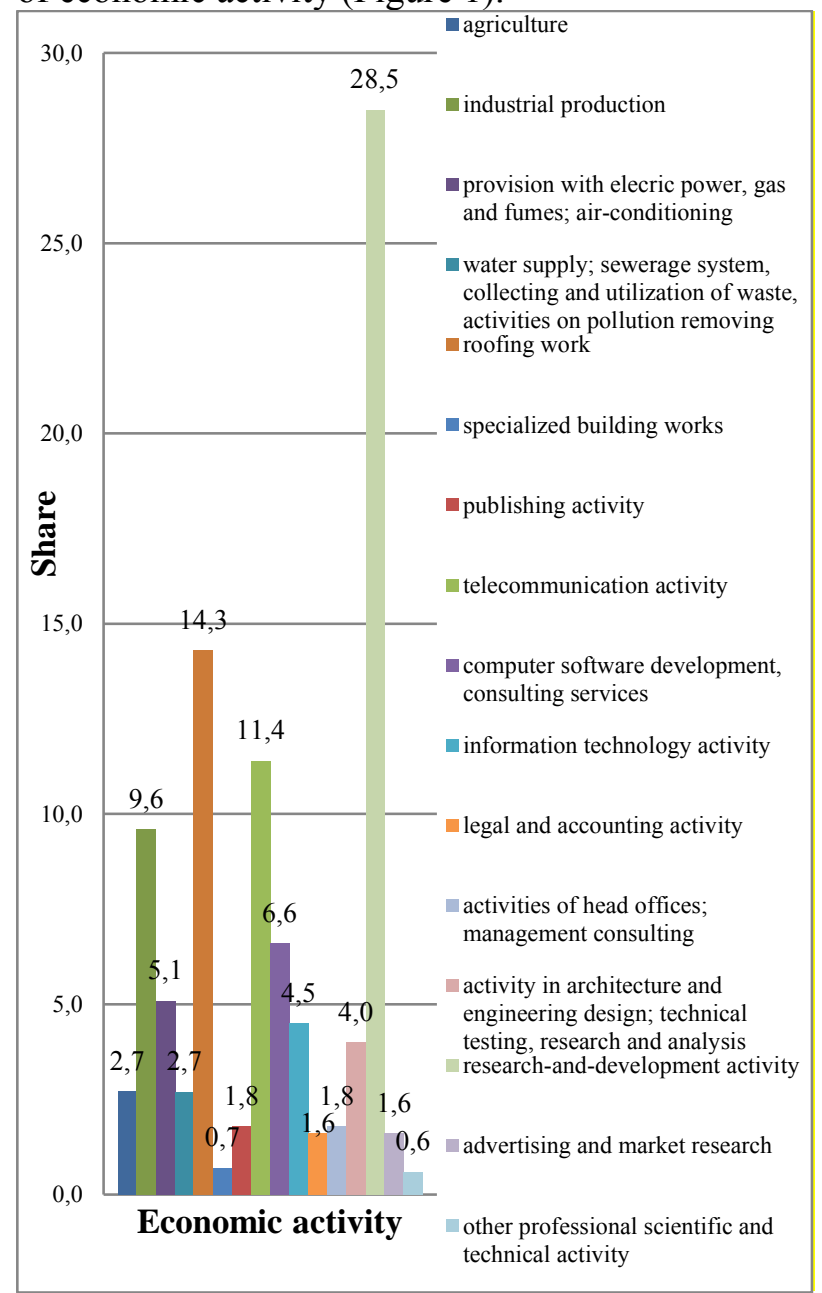

Figure 1. The share of organizations with technological innovations in 2017 in a total number of studied organizations in the RF and the type of economic activity

According to the Federal State Statistics Service, the largest share $(28.5 \%)$ of organizations engaged in technological innovations is observed in research and development organizations. A significant share of organizations $(14.3 \%)$ engaged in roofing works uses technological innovations in their activities. A high share of these innovations is observed in industrial production $(9.6 \%)$ and telecommunications $(11.4 \%)$. It should be noted that in agriculture, a share of organizations with technological innovations remains low (2.7\%). However, the use of these technologies, in particular robotics in agriculture, provides an increase in labor productivity [3] and lower production costs [4], [5].

It is possible to distinguish certain areas of agriculture in which organizations carry out technological innovations (Figure 2).

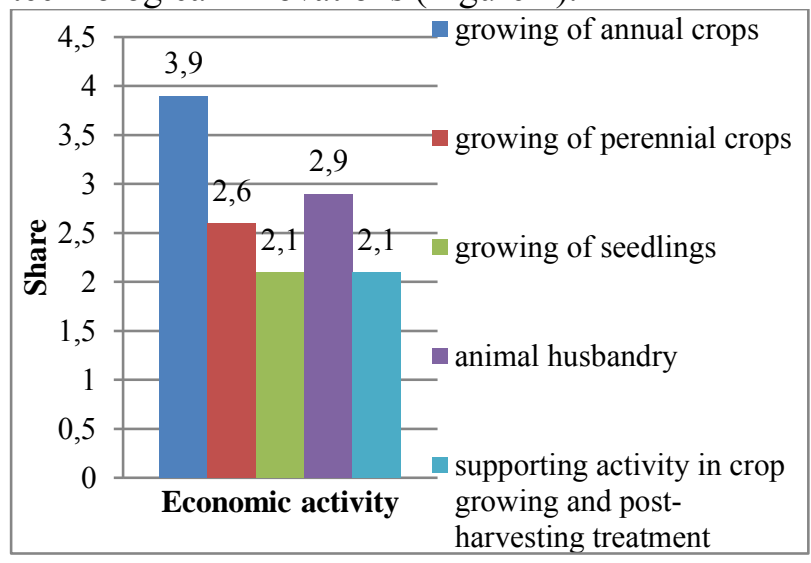

Figure 2. The share of agricultural organizations with technological innovations in 2017 in the RF

As the analysis shows, the largest share of technological innovations is observed in cultivation of annual $(3.9 \%)$ and perennial $(2.6 \%)$ crops. In livestock production, technological innovations are applied at $2.9 \%$ of organizations.

A low level of technological innovations used in agriculture, in particular robotics, makes it necessary to study these processes. It is possible to highlight some general characteristics of rural areas that may influence the implementation of technological innovations. Some authors point to increased unemployment and lower literacy rates at further areas [6]. In addition, an increased share of structural unemployment [7] and "hidden unemployment" [8], [9] are noted.

Primarily, it is necessary to carry out an analysis of the availability of agricultural personnel at the regions (table 1).

According to experts, the rural population will decrease in the medium and long term, while the negative process will increase. Currently, the rural population is 39.5 million people, or $27 \%$ of the population of Russia, about 21 million people or $53.2 \%$ is able-bodied. A significant number of rural people, 9.1 million people $(23 \%)$, are pensioners. According to expert assessments, the rural population in Russia, considering migration, will decrease by $4.6 \%$ by 2020 , and by $10.2 \%$ by 2040 . These demographic tendencies result in growing shortage of workers for agriculture.

The average annual number of people employed in agriculture, hunting and forestry; fisheries, fish farming is shown in table 1. 
Table 1. The average annual number of people employed in agriculture, hunting and forestry; fishing, fish farming, thousand people

\begin{tabular}{|l|c|c|c|c|c|c|c|}
\hline \multicolumn{1}{|c|}{ Area } & 2013 & 2014 & 2015 & 2016 & 2017 & $\begin{array}{c}\text { Average in } \\
2013-2007\end{array}$ & 2017 to 2005, \% \\
\hline Russian Federation & 6503 & 6386 & 5546 & 5502 & 5075 & 5802 & 78,0 \\
\hline Central federal district & 1223 & 1210 & 1018 & 1014 & 954 & 1084 & 78,0 \\
\hline $\begin{array}{l}\text { Northern-west federal } \\
\text { district }\end{array}$ & 383 & 372 & 322 & 323 & 290 & 338 & 75,7 \\
\hline Southern federal district & 977 & 953 & 938 & 912 & 844 & 925 & 86,4 \\
\hline $\begin{array}{l}\text { North Caucasus federal } \\
\text { district }\end{array}$ & 720 & 729 & 721 & 724 & 708 & 720 & 98,3 \\
\hline Volga federal district & 1618 & 1581 & 1269 & 1264 & 1123 & 1371 & 69,4 \\
\hline Ural federal district & 365 & 353 & 297 & 293 & 263 & 314 & 72,1 \\
\hline Siberian federal district & 924 & 904 & 751 & 738 & 669 & 797 & 72,3 \\
\hline Far Eastern federal district & 293 & 283 & 230 & 235 & 225 & 253 & 76,7 \\
\hline
\end{tabular}

According to the Federal State Statistics Service, as of January 1, 2018, in Russia as a whole, the average annual number of people employed in agriculture, hunting and forestry; fishing, fish farming was 5802 thousand people in 2013-2017. At the same time, the total number of employees in these spheres of activity decreased by $22 \%$ over the studied period. The number of employees in the Central federal district decreased by $22 \%$ and was more than 1 million people. The largest decline in employment in this sphere is observed in the Volga federal district $(30.6 \%)$, the Ural federal district $(27.9 \%)$ and the Siberian federal district $(27.7 \%)$.

The most stable number of people employed in agriculture, hunting and forestry; fisheries, fish farming is observed in the Southern federal district (a decrease by 13.6\%) and the North Caucasus federal district (a decrease only by 1.7\%). In the Far Eastern federal district, one can see the smallest number of employees that was 253 thousand people over the observed period. Thus, the Russian Federation has a steady tendency in decreasing the number of people employed in agriculture, hunting and forestry; fishing, fish farming.

At the same time, the State program on development of agriculture and regulation of agricultural products, raw materials and food markets for 2013-2020 specifies the production increase at farms of all categories in 2020 by $39 \%$ compared to 2010. To achieve this indicator, there will be a need in competent, technically trained and skilled in modern technologies human resources to carry out work, develop projects, manage complex processes, provide social services, etc. All these moments increase the feasibility of using labor- saving technologies, among which it is possible to speak about digital, intelligent and robotic

technologies.

\subsection{Agricultural robotization}

The data show that 393 units of robotics were introduced in agricultural organizations of the Russian Federation in 2006-2016 [10]. The vast majority of robotics used in agriculture in Russia is milking robots mainly of European manufacturers. The most famous manufacturers of this equipment are DeLaval (Sweden), Lely (Holland), Fullwood (Great Britain), GEA FarmTechnologies (Germany), SAC (Denmark). Lely feeders are used in several regions. There are other types of robots in various industries, but they are not widely used in Russia [11]. There is an analysis of introduction of robotics in agriculture by federal districts (Figure 3).

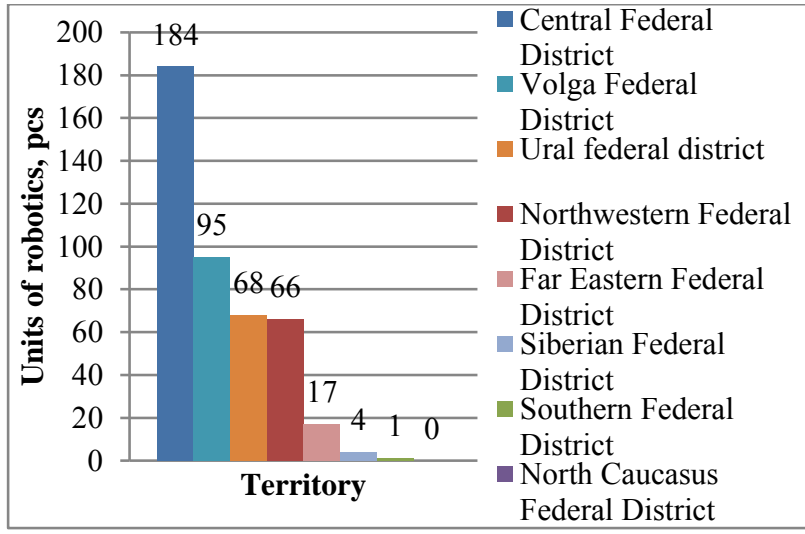

Figure 3. The units of robotics in agriculture by federal districts

As the figure shows, the largest number of 
robotics used in agriculture in the Russian Federation is observed in the Central federal district (184 units). Here, targeted activities are being carried out to robotize the industry in several regions at once. Robotics is used in the agricultural sector in the Volga (95 units), North-West (66 units) and Ural (68 units) federal districts. The introduction of robotics in agriculture is little in the Southern, Siberian and North Caucasian federal districts.

\section{Problem Solution}

The data on the number of robots and agricultural workers make it possible to calculate the density of agricultural robotization in the Russian Federation and its federal districts (Figure 3).

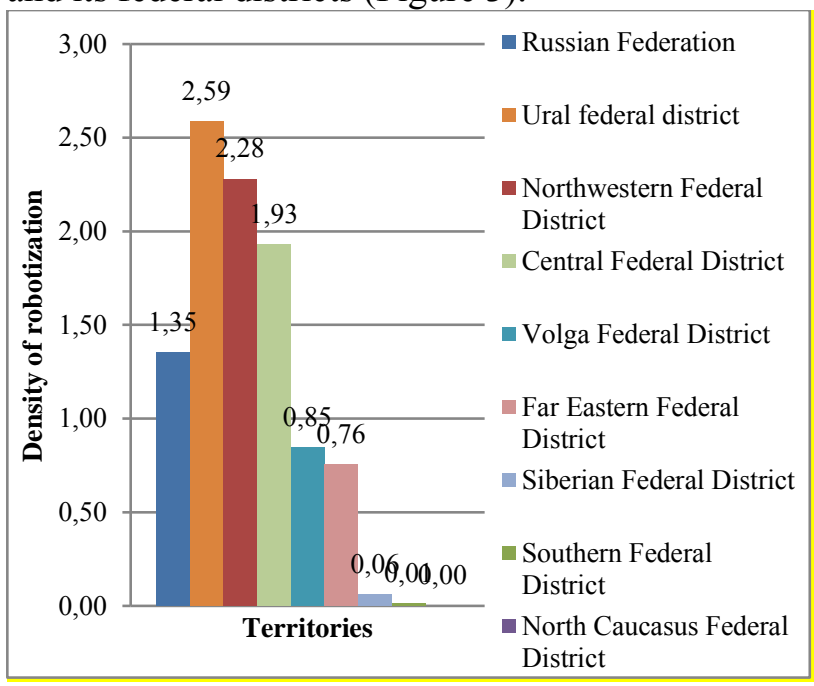

Figure 4. The density of robotizaion in agriculture in the RF and in its federal districts

According to the data one can see that on average in Russia, the density of agricultural robotization was 1.35 robots per 10 thousand workers. The highest indicator is observed in the Urals federal district, that may be due to the introduction of robotics in several regions at the same time and a low number of people employed in agriculture. High indicators are observed in the Far eastern federal district, which are caused by a low number of people employed in agriculture.

The data on the density of robotization in the regions and their ranking are in Figure 5.

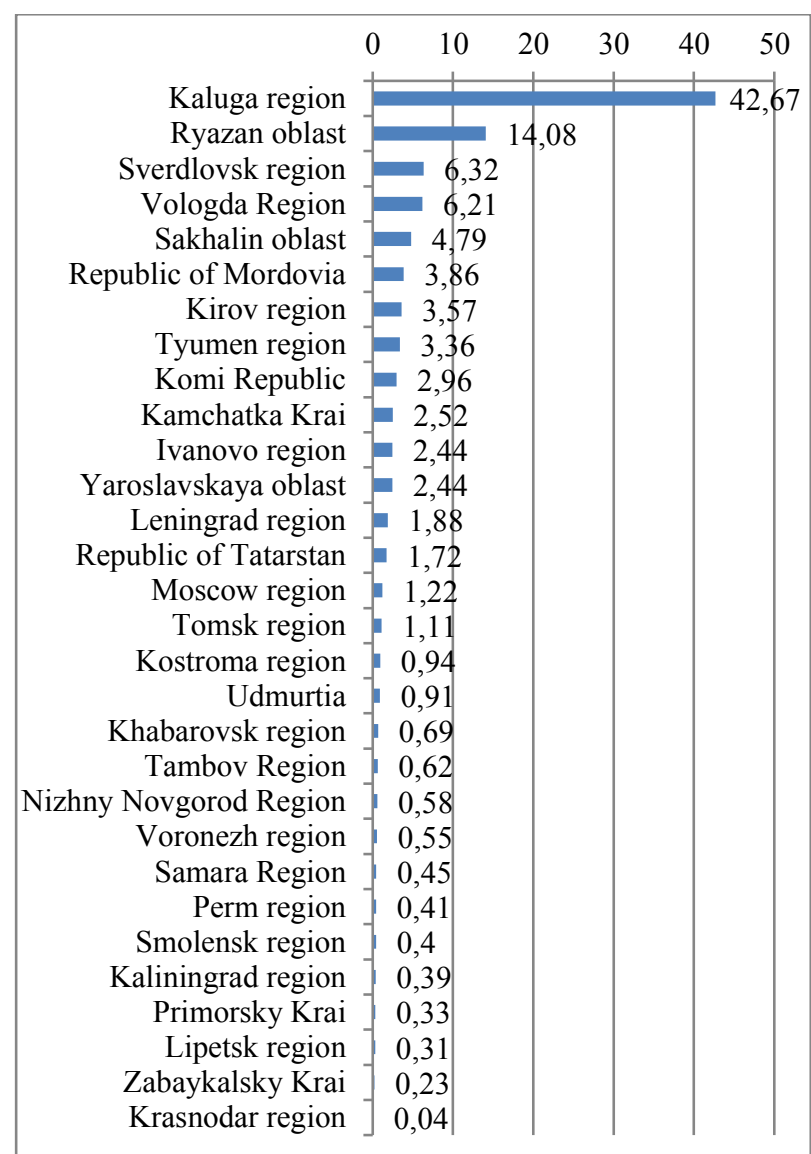

Figure 5 . The density of agricultural robotization in the regions of the Russian Federation, robots per 10 thousand employees in the industry

As the analysis shows, the highest density of agricultural robotization is in the Kaluga region (42.67 robots per 10 thousand people employed in the industry). The region has the state development program to make conditions for the development and modernization of the production base in dairy cattle breeding on the basis of innovative robotic technologies, to support a traditional sub-sector of agriculture, which is essential for the regional socioeconomic development. Significant density of agricultural robotization (14.08 robots per 10 thousand employees in the industry) is in the Ryazan region, due to the targeted efforts of a large agro-industrial holding. High indicators can be noticed in the Vologda region (6.21) in the Republic of Mordovia (3.86), the Sverdlovsk region (6.32) due to a traditionally developed dairy subcomplex of agriculture and a decrease in the number of people working in the industry.

According to the International Federation of Robotics (IFR), in terms of the density of robotization, the domestic agriculture and the country's economy as a whole are significantly behind not only the leading countries, but also the world average indicators. So, according to the 
results of 2017, the density of robotization in the leader-country, South Korea, was 631 robots per 10 thousand employees, while the global average indicator was 74 robots per 10 thousand employees. In Russia, this number is 3 robots per 10 thousand of employees.

So, it is possible to rank regions according to the density of agricultural robotization. The regions with the density of robotizatin which exceeds the average indicator in the Russian economy can be considered regions with a high density of robotization. The regions with the density of $0-3$ can be treated as regions with a medium level of robotization, and there is no such activity in some other regions.

\section{Conclusion}

The study results will contribute to the development of methodological and theoretical principles for the spatial development of agricultural robotics, carrying out a comprehensive analysis of the factors of robotics introduction in the agricultural sector of the rural economy in the conditions of a shortage of personnel. The data on the density of robotization in the Russian Federation and its regions will reveal new universal patterns of spatial development of robotics at the rural areas in accordance with various features. These features are: the availability of infrastructure, an isolated location from big cities, a share of the rural population, etc. Also, the results of the study allow identifying factors that impede robotization of the agricultural sector of the rural economy and offering recommendations to reduce their impact.

The scientific significance of the research results will contribute to the development of theoretical aspects of application of robotics in agriculture and the spatial aspects of robotization. These results can be used in further research on application of robotics in the agricultural sector of the economy. The applied significance of the study involves the possibility of using the results by managers and professionals at agricultural organizations for the economic feasibility and a choice of robotic technologies to reduce the dependence of farms on staff shortages and the influence of the human factor on the results of agricultural production. This will increase the innovative activity of organizations at rural areas; reduce the influence of factors that have negative affect on robotization of the agricultural sector at the proper areas

\section{Acknowledgments/ Financing}

The study was funded by RFBR, a project number is 20-010-00636 A «Spatial development of agricultural robotization in Russia: trends, factors, mechanisms»

\section{References:}

[1] M.M. Panov, Intraregional typology of rural areas (by the example of the Vologda region), Development problems of territories, № 2 (76), 2015, pp. 159-173

[2] V.I. Bugromenko, The economic assessment of transport-geographical position of economic entities, Journal of Academy of sciences of USSR, №5, 1981, pp. 66-79

[3] A. Castro, J.M. Pereira, C. Amiama, J. Bueno, Estimating efficiency in automatic milking systems, Journal of Dairy Science, Vol. 95, 2012, Pp. 929-936 DOI: 10.3168 / jds.2010-3912.

[4]C. Tse, H.W. Barkema, T. J. DeVries, J. Rushen, E.A. Pajor. Impact of automatic milking systems on dairy cattle producers' reports of milking labour management, milk production and milk quality, Published online by Cambridge University Press, 2018, pp. $1-8$

[5] Aykut Örs, Cennet Oğuz. Comparison of the Economic Performance of Robotic Milking System and Conventional Milking System Manas, Journal of Agriculture Veterinary and Life Sciences, Vol. 8 (2), 2018, pp. 35 - 51.

[6] Monnat, Shannon M. Pickett, Camille Beeler Rural Urban differences in self-rated health: Examining the roles of county size and metropolitan adjacency, HEALTH \& PLACE, Vol. 17 No.1, 2011, pp. 311-319

[7]Z.I. Kalugina, O.P. Fadeyeva, A new paradigm of agricultural development, The world of Russia, № 2, 2009, pp. 34-49

[8]R.I. Kapelyushnikov, Informal employment in Russia: what alternative definitions say, New economic association, №4, 2013, pp. 52-84

[9]D. Bögenhold, R. Klinglmair, F. Kandutsch, Solo Self-Employment, Human Capital and Hybrid Labour in the Gig Economy, Foresight and STI Governance, Vol. 11, No 4, 2017, pp. 23-32 DOI: 10.17323/2500-2597.2017.4.23.32

[10] E.A. Skvortsov, E.G. Skvortsova, I.S. Sandu, G.A. Iovlev, Transition of agriculture to digital, intelligent and robotic technologies, Regional economy, Vol. 14, issue 3, 2018, pp. 1014-1028

DOI:10.17059/2018-3-23

[11] A.N. Syomin, E.A. Skvortsov, E.G. Skvortsova, Territorial aspects of robotization of 
agriculture of the AIC: economy, management, № 3, 2019, pp. 35-46.

Contribution of individual authors to the creation of a scientific article (ghostwriting policy):

Vladimir NABOKOV, Alexsei GUSEV Developed a research methodology.

Egor SKVORTCOV, Alexsander SEMIN has Performed calculations of section 3.

Natalia PRYADILINA, Konstantin NEKRASOV was responsible for the Statistics.

Follow: www.wseas.org/multimedia/contributorrole-instruction.pdf

\section{Creative Commons Attribution}

\section{License 4.0 (Attribution 4.0}

International , CC BY 4.0)

This article is published under the terms of the Creative Commons Attribution License 4.0

https://creativecommons.org/licenses/by/4.0/deed.en US 